\title{
Peptides in BioNMR Research
}

\author{
Oliver Zerbe*, Christian Baumann, Matthias Schuster, Kerstin Moehle, Kathryn K. Oi, and Erich Michel
}

\begin{abstract}
Heteronuclear NMR in combination with isotope labelling is used to study folding of polypeptides induced by metals in the case of metallothioneins, binding of the peptidic allosteric modulator $\rho$-TIA to the human G-protein coupled $\alpha_{1 \mathrm{~b}}$ adrenergic receptor, the development of therapeutic drugs that interfere with the biosynthesis of the outer membrane of Gram-negative bacteria, and a system in which protein assembly is induced upon peptide addition. NMR in these cases is used to derive precise structural data and to study the dynamics.
\end{abstract}

Keywords: Antibiotic · GPCRs · NMR · Lpt · Repeat protein

Peptides often perform important biological functions that are mediated by specific contacts between them and their receptors and hence a detailed understanding of their structure is of prime importance. Herein, we briefly present four examples from our lab that comprise: i) metalation of a small metalloprotein with defined metal clusters, ii) a peptide that acts as an allosteric modulator to a human $\mathrm{G}$ protein-coupled receptor (GPCR), iii) peptide antibiotics with a novel mode-of-action, and iv) peptide-induced and controllable formation of protein-protein complexes.

\section{Metal Uptake in Gastropod Metallothioneins}

Metallothioneins (MTs) are polypeptides with the capability of binding a large number of metal ions, thereby allowing cells to efficiently immobilize toxic heavy metal ions such as Cd. ${ }^{[1]}$ Through the uptake of metal ions, MTs adopt a defined fold, while they are unfolded in the apo-state. Most MTs described so far are organized into two domains that are separated by a short linker. These domains are roughly 30 amino acids in length and bind 3 or 4 divalent metal ions by coordination to 9 or 11 cysteines, respectively.

MTs in gastropods, which include snails and slugs, sometimes possess one to eight extra domains due to duplications of the N-terminal domain, ${ }^{[2]}$ which provides these MTs with an increased metal-loading capacity. In the common periwinkle (Littorina littorea) MT (L1MT) the two N-terminal domains display $79 \%$ sequence identity. The center and the C-terminal domains are tightly coupled, whereas the $\mathrm{N}$-terminal domain seems to be less restricted. ${ }^{[3]}$ We have followed incorporation of $\mathrm{Zn}$ and $\mathrm{Cd}$ ions into the protein by $\left[{ }^{15} \mathrm{~N},{ }^{1} \mathrm{H}\right]-\mathrm{HSQC}$ experiments. These titrations revealed that the metal ions are preferably bound by the C-terminal domain, with little difference in affinity for the homologous two N-terminal domains. ${ }^{[4]}$ Metals are bound in a cooperative fashion, and no partially metallated domains are detected in the spectra. However, additional signals indicate the presence of partially folded LIMTs with only one or two metallated domains.

In the gastropod lineage Heterobranchia, different MT isoforms evolved to cope with different metal ions. For example, the roman snail (Helix pomatia) has three isoforms, each with a different metal binding preference (one specific for $\mathrm{Cd}^{2+}$, one for $\mathrm{Cu}^{+}$, and one that is unspecific). ${ }^{[5]}$ Measuring ${ }^{15} \mathrm{~N}$ transverse relaxation rates (R2) we could demonstrate that the $\mathrm{Cd}$-selective Helix pomatia MT (Cd-HpMT) evolved to bind $\mathrm{Cd}$ ions more

${ }^{\star}$ Correspondence: Prof. O. Zerbe, E-mail: oliver.zerbe@chem.uzh.ch Department of Chemistry, University of Zurich,

Winterthurerstrasse 190, Zurich, Switzerland efficiently than $\mathrm{Zn}$ ions (Fig. 1), ${ }^{[4]}$ as increased $\mathrm{T} 2$ rates due to conformational exchange processes are observed in the Zn-loaded species. We suspect that the transition between environments with different metal exposure during the evolution of gastropods was the driving force behind shaping this type of metal binding preferences. ${ }^{[4]}$

\section{Differences between $\mathrm{Zn}_{6}$ and $\mathrm{Cd}_{6}-\mathrm{HpMT}_{\mathrm{T}} 2$ Rates}

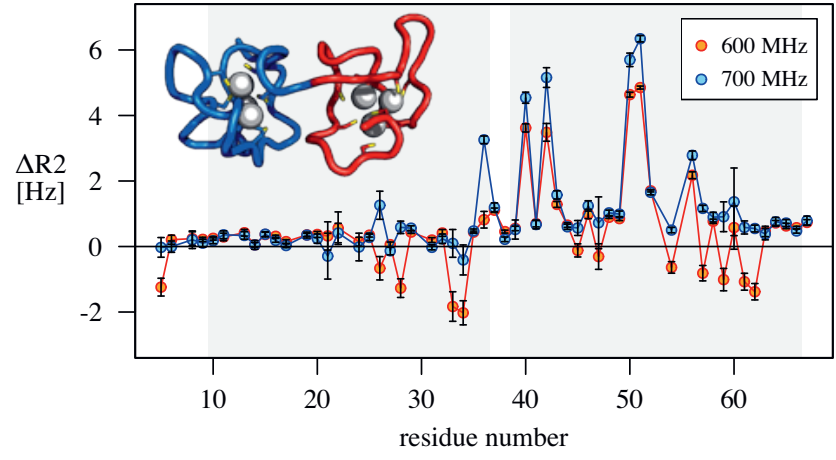

Fig. 1. The differences in ${ }^{15} \mathrm{~N}$ T2 relaxation rates between $\mathrm{Cd}$ and $\mathrm{Zn}$ coordinating Helix pomatia metallothioneins. Positive values indicate increased conformational exchange in the $\mathrm{Zn}$ loaded MT. Rates were measured at 600 (red) and 700 (blue) MHz. The structure of HpMT highlights the $\mathrm{N}$-terminal (blue) and the C-terminal domains (red).

\section{The Conopeptide $\rho$-TIA is an Allosteric Modulator of the GPCR $\alpha_{1 \mathrm{~b}}$-Adrenergic Receptor}

The venom of cone snails consists of up to 200 different conopeptides that are highly specific for many different targets, including multiple ion channels and receptors. ${ }^{[6]}$ The conopeptide $\rho$-TIA from the cone snail Conus tulipa is 19 amino acids in length and forms two disulfide bonds. It acts as allosteric inverse agonist on $\alpha_{1}$-adrenergic receptors ( $\alpha_{1}$-ARs), which belong to the rhodopsinlike class of $\mathrm{G}$ protein-coupled receptors (GPCRs). ${ }^{[7]}$ By targeting these receptors, $\rho$-TIA leads to a strong drop in blood pressure of the fish preyed upon by the snail. This conopeptide is further able to distinguish between the different subtypes of $\alpha_{1}$-ARs, ${ }^{[8]}$ which might help to improve the design of drugs selective for specific receptor subtypes. We have studied the interaction of $\rho$-TIA with the $\alpha_{1 b}$-AR by solution NMR. Since GPCRs are thermally unstable and express badly, it was necessary to introduce 13 mutations and to truncate the termini as well as the intracellular loop 3 to produce a construct of the $\alpha_{1 \mathrm{~b}}$-AR that can be investigated 
by NMR. ${ }^{[9]}$ This construct was optimized for the expression in $E$. coli, which allows straight-forward labeling schemes for methyl groups and backbone amides.

Small orthosteric ligands bind inside the helix bundle at the extracellular half of the receptor, whereas $\rho$-TIA binds allosterically at the extracellular ends of helix 6 and 7. Binding of $\rho$-TIA to $\alpha_{1 \mathrm{~b}}$-AR increases the stability of the receptor and improves the quality of the spectra when compared to the apo receptor (Fig. 2). The better signal dispersion and the reduced line widths obtained with $\rho$-TIA indicate that the peptide is able to reduce the dynamic behavior of the apo $\alpha_{1 \mathrm{~b}}$-AR by locking the receptor in an inactive conformation.

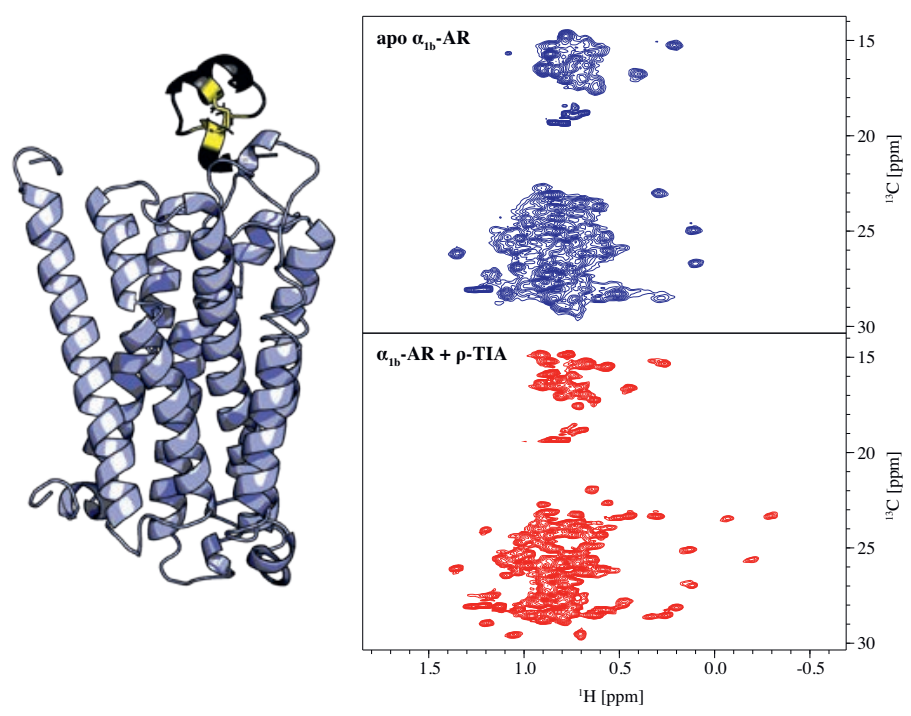

Fig. 2. $\left[{ }^{13} \mathrm{C},{ }^{1} \mathrm{H}\right]-\mathrm{HSQC}$ spectra of ILV-labelled $\alpha_{1 \mathrm{~b}}$-AR in deuterated MNG micelles in the apo state (blue) and binding $\rho$-TIA (red). Spectra were recorded at $700 \mathrm{MHz}$, and at $27^{\circ} \mathrm{C}$ and $47^{\circ} \mathrm{C}$ for the apo and the $\rho$-TIA sample, respectively. The structure model shows $\rho$-TIA in black with cysteines highlighted in yellow.

\section{Development of Peptide Antibiotics Targeting LPS Biosynthesis}

Antibiotic resistance is an emerging problem due to the widespread (mis)use of antibiotics in the treatment of infections. The World Health Organization (WHO) has defined a list of pathogens known as ESKAPE (Enterococcus faecium, Staphylococcus aureus, Klebsiella pneumoniae, Acinetobacter baumannii, Pseudomonas aeruginosa, and Enterobacter spp.) for which many antibiotic-resistance strains have been observed worldwide. [10] These pathogens are responsible for many hospital-acquired infections. Unfortunately, no antibiotic with a novel mode-of-action has been marketed since the introduction of the topoisomerase inhibitors such as ciprofloxacin in the 1960s. The group of John Robinson from our institute and in collaboration with the Baselbased drug discovery company POLYPHOR published a study in 2010 describing the discovery of a cyclic peptide based on the scaffold of the naturally occurring peptide protegrin. ${ }^{[11]}$ The peptide, developed under the name Murepavidin, selectively binds to the LptD-LptE complex. LptD is an outer membrane beta-barrel protein that is part of the lipopolysaccaride (LPS) transport pathway. LPS is the most abundant component on the cell surface of Gram-negative bacteria. The LPS transport (Lpt) protein family consists of seven proteins, LptA-LptG, which facilitates the transfer of LPS from the inner membrane to the outer membrane (Fig. 3A). ${ }^{[12]}$ Addition of Murepavedin to growth media resulted in accumulation of membrane-type materials such as LPS and lipids in intracellular compartments triggering cell death. Unfortunately, Murepavadin was stopped in phase III of a clinical trial due to high incidence of acute kidney injury. The drug has since been developed as an inhaled formulation to treat people with cystic fibrosis. ${ }^{[13,14]}$

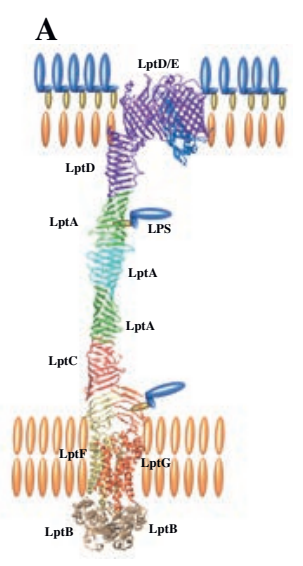

B

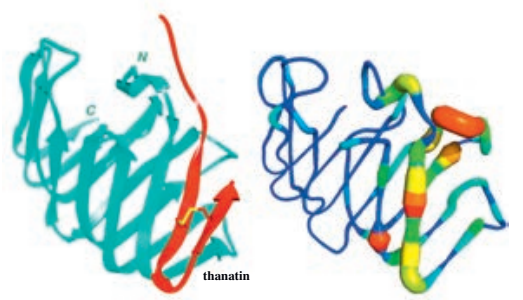

Fig. 3. A: Protein bridge of the Lpt system. B: complex of LptA (cyan) bound to Thanatin (red). C: CSPs upon binding to Thanatin mapped as the spline radius and with color-coding on LptA.

In a follow-up study, Robinson and coworkers discovered that the already known peptide Thanatin from the spined soldier bug binds to LptA (Fig. 3B,C). ${ }^{[15]}$ LptA forms oligomers with itself in a head-to-tail fashion and thereby bridges the periplasmic space.[12] Our group solved the NMR structure of the LptA-Thanatin complex, and proposed that Thanatin replaces LptA-LptA or LptA$\mathrm{LptC}$ interactions and thereby disrupts the protein bridge formation. ${ }^{[15]}$ Thanatin cannot be used as an antibiotic due to its proteolytic instability, unfavorable pharmacokinetic properties and rapid formation of bacterial resistances. In collaboration with POLYPHOR, we currently study synthetic Thanatin-inspired derivatives with significantly improved antimicrobial activity, pharmacokinetic properties and resistance profiles. The new antibiotic candidates show an attractive antimicrobial profile by covering the WHO priority 1 carbapenem- and third generation cephalosporinresistant Enterobaceriaceae family. Furthermore, they show no cross-resistance with standard of care antibiotics. Chemical shift perturbation (CSP) data of these new peptides reveal the same binding mode as Thanatin.

\section{Playing Protein Origami}

Peptides often serve as ligands to proteins. We have recently exploited this function in order to trigger peptide-induced assembly of protein complexes. ${ }^{[16]}$ The protein system is based on the observation that Armadillo repeat proteins, a class of proteins with repetitive amino acid sequence that contains a number of structurally almost identical modules, assemble, when expressed in two pieces, into the same structure as the single chain protein. ${ }^{[17]} \mathrm{We}$ have then engineered the two fragments to reduce the affinity to bind to each other. ${ }^{[16,18]}$ As a result they only form the protein complex when a peptide ligand is present that binds to both fragments in the complex. Using amino-acid specific isotope labelling[19] and heteronuclear NMR experiments we could then demonstrate that in a mixture of one C-terminal with a number of different $\mathrm{N}$-terminal fragments addition of a peptide ligand selects for formation of the complex with the highest affinity for the peptide with surprisingly high selectivity (Fig. 4). ${ }^{[16]}$ Such a system allows to create macromolecular structures reminiscent of DNA origami in a controlled fashion. By fusing the peptide ligand to other proteins, in particular to generic binders of other molecules, we are now developing this system into a macromolecular assembly of 
defined composition that allows to place proteins in defined distances to one another.

A

$$
\text { B }
$$
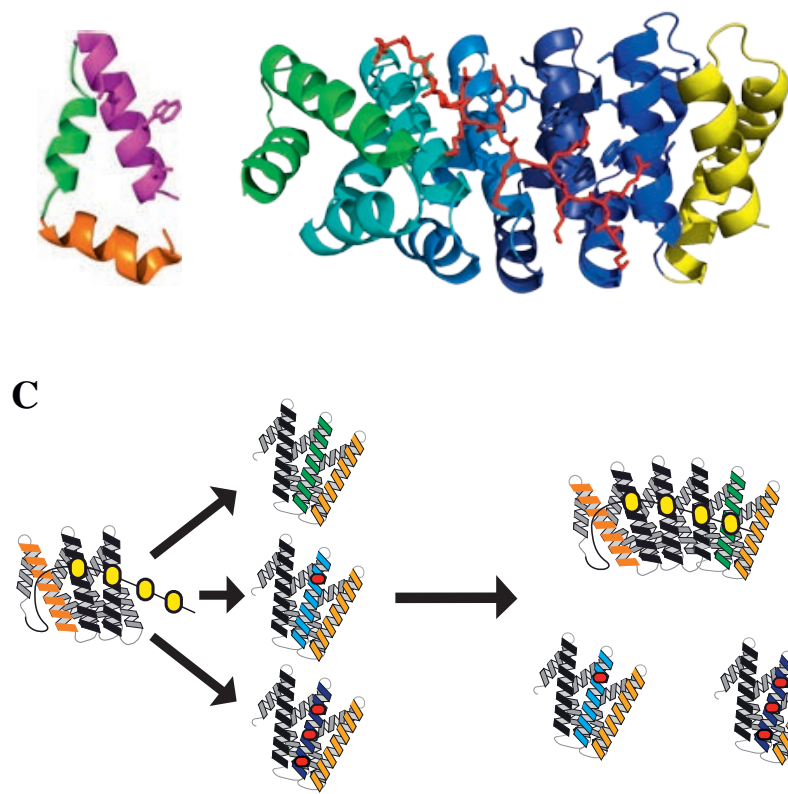

Fig. 4. A: Structure of a single internal repeat of ArmRPs. B: Structural model of the complex between $(\mathrm{KR})_{4}$ (red sticks) and a NM ${ }_{4} \mathrm{C}$ ArmRP. $\mathrm{C}$ : Mixing of a target peptide fused to an $\mathrm{N}$-terminal fragment with various C-terminal fragments results in preferential enrichment of the best target peptide binder (see text).

All the described projects involve peptides and exploit heteronuclear NMR in one way or another to determine folding or the binding mode between the peptides and proteins in order to determine structures and to derive information on dynamics of the protein or their complexes. Using NMR and isotope labelling in our research endeavors is crucial because many of the abovedescribed systems contain flexible parts and hence are inherently difficult to crystallize.

Received: April 6, 2021

[1] C. A. Blindauer, O. I. Leszczyszyn, Nat. Prod. Rep. 2010, 27, 720, https://doi.org/10.1039/B906685N.

[2] V. Pedrini-Martha, S. Köll, M. Dvorak, R. Dallinger, Int. J. Mol. Sci. 2020, 21, 21, 1631, https://doi.org/10.3390/ijms21051631.

[3] C. Baumann, A. Beil, S. Jurt, M. Niederwanger, O. Palacios, M. Capdevila, S. Atrian, R. Dallinger, O. Zerbe, Angew. Chem. Int. Ed. 2017, 56, 4617, https://doi.org/10.1002/anie.201611873.
[4] R. Dallinger, O. Zerbe, C. Baumann, B. Egger, M. Capdevila, Ò. Palacios, R. Albalat, S. Calatayud, P. Ladurner, B. C. Schlick-Steiner, F. M. Steiner, V. Pedrini-Martha, R. Lackner, H. Lindner, M. Dvorak, M. Niederwanger, R. Schnegg, S. Atrian, Metallomics 2020, 12, 702, https://doi.org/10.1039/c9mt00259f.

[5] R. Dallinger, B. Berger, P. Hunziker, J. H. R. Kägi, Nature 1997, 388, 237 , https://doi.org/10.1038/40785.

[6] S. Becker, H. Terlau, Appl. Microbiol. Biotechnol. 2008, 79, 1, https://doi.org/10.1007/s00253-008-1385-6.

[7] L. Ragnarsson, C. I. Wang, Å. Andersson, D. Fajarningsih, T. Monks, A. Brust, K. J. Rosengren, R. J. Lewis, J. Biol. Chem. 2013, 288, 1814, https://doi.org/10.1074/jbc.M112.430785.

[8] Z. Chen, G. Rogge, C. Hague, D. Alewood, B. Colless, R. J. Lewis, K. P. Minneman, J. Biol. Chem. 2004, 279, 35326 , https://doi.org/10.1074/jbc.M508651200

[9] M. Schuster, M. Deluigi, M. Pantić, S. Vacca, C. Baumann, D. J. Scott, A. Plückthun, O. Zerbe, Biochim. Biophys. Acta Biomembr. 2020, 1862, 183354, https://doi.org/10.1016/j.bbamem.2020.183354.

[10] WHO, 2017, https://www.who.int/news/item/27-02-2017-who-publisheslist-of-bacteria-for-which-new-antibiotics-are-urgently-needed

[11] N. Srinivas, P. Jetter, B. J. Ueberbacher, M. Werneburg, K. Zerbe, J. Steinmann, B. Van der Meijden, F. Bernardini, A. Lederer, R. L. Dias, P. E. Misson, H. Henze, J. Zumbrunn, F. O. Gombert, D Obrecht, P. Hunziker, S. Schauer, U. Ziegler, A. Kach, L. Eberl, K Riedel, S. J. DeMarco, J. A. Robinson, Science 2010, 327, 1010, https://doi.org/10.1126/science.1182749.

[12] E. Lundstedt, D. Kahne, N. Ruiz, Chem Rev. 2020, in press, https://doi.org/10.1021/acs.chemrev.0c00587.

[13] G. Upert, A. Luther, D. Obrecht, P. Ermert, Med. Drug Discov. 2021, 9 , 100078, https://doi.org/10.1016/j.medidd.2020.100078.

[14] M. Díez-Aguilar, M. Hernández-García, M. I. Morosini, A. Fluit, M. M. Tunney, N. Huertas, R. Del Campo, D. Obrecht, F. Bernardini, M. Ekkelenkamp, R. Cantón, J. Antimicrob. Chemother. 2021, 76, 984, https://doi.org/10.1093/jac/dkaa529.

[15] S. U. Vetterli, K. Zerbe, M. Müller, M. Urfer, M. Mondal, S. Y. Wang, K. Moehle, O. Zerbe, A. Vitale, G. Pessi, L. Eberl, B. Wollscheid, J. A. Robinson, Sci. Adv. 2018, 4, eaau2634, https://doi.org/10.1126/sciadv.aau2634.

[16] E. Michel, A. Plückthun, O. Zerbe, Angew. Chem. Int. Ed. 2018, 57, 4576, https://doi.org/10.1515/hsz-2018-0355.

[17] R. P. Watson, M. T. Christen, C. Ewald, F. Bumbak, C. Reichen, M Mihajlovic, E. Schmidt, P. Güntert, A. Caflisch, A. Plückthun, O. Zerbe, Structure 2014, 22, 985, https://doi.org/10.1016/j.str.2014.05.002.

[18] E. Michel, A. Plückthun, O. Zerbe, Biol. Chem. 2019, 400, 395 , https://doi.org/10.1515/hsz-2018-0355.

[19] E. Michel, F. H. Allain, Methods Enzymol. 2015, 565, 389, https://doi.org/10.1016/bs.mie.2015.05.028.

\section{License and Terms}

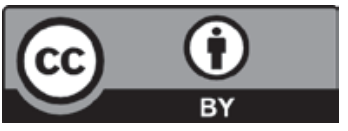

This is an Open Access article under the terms of the Creative Commons Attribution License CC BY 4.0. The material may not be used for commercial purposes.

The license is subject to the CHIMIA terms and conditions: (http:// chimia.ch/component/sppagebuilder/?view=page $\& i d=12$ ).

The definitive version of this article is the electronic one that can be found at https://doi.org/10.2533/chimia.2021.505 